\title{
Exploration of the Teaching Reform of Pharmacological Experiment Class Based on the "Open Teaching" Mode
}

\author{
Zhao Yuqin, Sun Kunlai, Chen Yin, Wang Bin, Qu Youle \\ School of Food and Pharmacy \\ Zhejiang Ocean University \\ Zhoushan, Zhejiang 316000, China
}

\begin{abstract}
Pharmacological experiment teaching plays a significant role in the cultivation of students. It can not only verify theoretical knowledge and achieve specific research goals, but also develop students' scientific research ideas and improve their innovative ability and comprehensive quality. Open-ended experiments for undergraduates are conducive to stimulating students' interest in learning and improving students' ability to discover, analyze and solve problems. Furthermore, it is extremely important to cultivate students' comprehensive quality and enhance students' innovation consciousness and practical ability. Implementing all-round and multi-level open teaching is the inevitable trend and development direction of experimental te aching reform.
\end{abstract} reform

Keywords-open-ended; experimental teaching; teaching

\section{INTRODUCTION}

The study on the open experimental teaching mode can be traced back to the 1960s [1]. In the traditional experimental teaching process, teachers arrange basically everything before class from the preparation of the experimental process to the determination of experimental plan while students only accept and emulate in a passive manner, which is fundamentally not conducive to mobilizing students' innovative enthusiasm. The traditional experimental teaching mode can no longer meet the needs of the current diversified society for students' hands-on ability, innovation ability and competitiveness. Compared with the traditional and closed experimental teaching, openended experiment emphasizes the opening of experiment time, content and teaching methods and students have the right to choose independently, which can create a good external environment for students' active learning and personality development while reflecting the people-oriented teaching concept at the same time [2-4]. Studies have shown that open experimental teaching can help foster students' scientific research interest and comprehensive quality, and improve the teamwork ability, ability of expression and ability to solve problems among undergraduates. In recent years, open experimental teaching has also attracted the attention of domestic educators [5-6] and many colleges and universities have tried to carry out the teaching mode accordingly. Universities have offered different open experiments at comprehensive, innovative, designable and some other different levels according to the difference of students' knowledge structure, which has achieved certain effects while it has also ignored the simultaneous implementation of the experimental management model reform. Experimental teaching is a rather complex system, including the laboratory hardware condition system, the process system with teaching activities as the basic content and the experimental teaching management system. Among them, conditional system is the basis; process system is the main body; and management system is the guarantee. Therefore, the quality of experimental teaching is based on the quality of work of every subsystem. If we want to reform and improve the quality of experimental teaching, we will first carry out reform of the laboratory management model, integrating and optimizing laboratory resources. It is of great significance for the cultivation of undergraduates to explore new modes of open experimental teaching actively and make new attempts of the experimental teaching mode.

\section{REFORM ExPERIMENTAL TEACHING Mode AND ReAlize OPEN EXPERIMENTAL TEACHING}

In the practice of experimental teaching, the undergraduates majoring in pharmacy and biopharmaceutics have carried out reform of open experimental teaching towards pharmacological experiments and have achieved some results. The open experiment is classified into three levels--the first level is the basic experiment, which is aimed at the lower grade students; the second level is the comprehensive experiment, which is mainly for the students who are interested in; the third level is the research design experiment mainly for the excellent students in the senior year. At the same time, it carries out different levels of open experiment combining innovation activities for college students, undergraduate thesis and research work of teachers. The open experiment opens both time and the experimental content to students, hence forming a good mechanism for individualized education of students and offering assistance to the innovative capabilities of students.

\section{ReFORM the EXPERIMENTAL TEACHING MethOD}

The selection of experimental projects and the design of experimental schemes should be based on the goal of enlightening students' scientific thinking and innovative 
consciousness. It is supposed to improve experimental teaching method continuously and set up a student-centered experimental teaching model of pharmacology, forming a learning approach with the main method of autonomous, research-based and cooperative learning. It improves the students' experimental ability and stimulates the interest in experiment to introduce advanced experimental teaching methods and modern technology, and offer experimental teaching by integrating a variety of auxiliary methods as well as coordinate assessment of the experimental results and process.

According to the characteristics of pharmacological experiments, students are able to master experimental techniques and skills through various forms of pharmacological practice training. In this way, students develop ideas, experience and understand the research process, possessing the ability to analyze and solve problems and the attainment of carrying out scientific experiments. The adopted experimental teaching methods are as follows:

1. Basic and confirmatory experiments. The teachers mainly lecture on the basic principles and operations of the experiment to the students, focusing on the cultivation of basic skills; and the students independently complete the experimental operation training and data measurement on the basis of previewing the experimental lectures in advance and then write an experimental report after class.

2. Comprehensive, design-oriented and inno vative research experiments. Students are divided into groups and a group contains 3 to 4 students. Under the guidance of experimental teachers, the students learn relevant theoretical knowledge and understand the experimental background at the beginning; they review the literature by themselves, design and complete the experimental program and solution configuration, prepare instruments and experimental materials, count and analyze statistics, discuss experimental results and so forth, and they write a research report after the experiment.

3. Forms of scientific research training. According to students' interest in a scientific research issue, the teachers instruct students to search for scientific papers, guide them to summarize and conclude the materials they have mastered, and write review papers. In this way, the teachers can cultivate the ability to propose and analyze problems of students, help them understand the latest scientific frontiers in the discipline and develop students' interest in scientific research.

\section{Reform the Assessment Mechanism Model AND IMPROVE THE EVALUATION SYSTEM OF STUDENT'S EXPERIMENTAL PERFORMANCE}

The experimental class assessment system is an effective way to guide undergraduate students to improve their learning methods. Therefore, the establishment and improvement of a scientific experimental class assessment mechanism is of great significance for guiding students to improve their own scientific research quality and innovative thinking and ability in the process of pharmacology experiment.

1. The basic experiment adopts the experimental whole process evaluation method, namely the experimental preparation process accounts for $10 \%$, the operation process accounts for $70 \%$ and the experimental report accounts for $20 \%$;

2. In the comprehensive experimental assessment, students are free to select the experimental content that they are interested in as the experimental assessment topic. The students complete the experiment as required, and submit the summary report as the content of assessment in the form of paper;

3. In terms of assessment of the research and designoriented experiment, teachers assign an experiment program to students (you can also select it yourself). The students design the experiment plan and complete the whole process of the experiment autonomously. Finally, they submit the experiment report as the content of the assessment.

\section{The Advantages of the Development of Open EXPERIMENTAL TEACHING}

1. Through the development of open experimental teaching, the innovative teaching philosophy and new teaching methods of teachers and students are established. Based on the psychological characteristics of college students, the teaching mode adopts the "reading guide and discovery method" in the pedagogy theory, proposing the classroom experiment and the open laboratory teaching mode with the design-oriented experiment as the core. The traditional experimental teaching method is replaced by the open experimental teaching mode focusing on design and comprehensiveness. The teaching mode aims to develop the basic ability of and interest in scientific research of students through multi-faceted and multilevel content design in the experimental teaching. More and more undergraduate students will participate in extracurricular academic science and technology competitions vigorously, such as the University Students Innovation Engineering Design Competition, the "Challenge Cup" and the Experimental Skills Competition.

2. Promote simultaneous reform of laboratory management model and experimental teaching model. The open experimental teaching system is driven by the reform of experimental teaching methods, aiming to greatly improve the innovation ability and comprehensive quality of undergraduates. It is guaranteed by the reform of the laboratory management mechanism, and we carry out allround reform coordinately of the laboratory management mode, multimedia experiment teaching courseware development, comprehensive and design-oriented experiments and some other aspects. This requires teachers to integrate and update the experimental teaching content and write new teaching materials; the construction and management mode of the laboratory faculty must change simultaneously, namely the personnel should be optimized and grouped. It is necessary to ensure that the experimental instruments and equipment are matched and intact, and at the same time, the scientific consumables should be scientifically controlled to ensure the reasonable use of experimental funds, avoiding unnecessary waste and achieving efficient operation of the entire laboratory. This move has improved the level of experimental management in universities. 
3. Promote the development of research-based experiments among undergraduate students. Research-based experiment is an experimental teaching form that combines open experimental teaching with scientific research training while integrating diverse teaching forms. Research-based experimental teaching is focused more on the training of scientific research ability and the cultivation of innovative thinking of students, basically carrying out in an open experiment or in combination with the content of scientific research topics synchronously. Through the open experimental teaching, the students' comprehensive ability will be greatly improved, and more outstanding students will participate in the research. Under the guidance of the teachers, they will choose research topics, design their own experimental programs and complete the research content. In this way, the students are able to understand the frontier field of discipline development, and at the same time, their awareness of scientific research and innovation and the practical ability to engage in scientific research will be cultivated.

\section{CONCLUSION}

Experimental teaching of pharmacy major is a crucial part of the cultivation of innovative pharmacy talents, and it is also an important component of pharmacy major-related courses. The open pharmacology experimental teaching mode focuses on cultivating students' inquiring and independent learning methods, and inspiring comprehensive design concepts of students. Students receive multi-faceted training during the experiment process. They can flexibly apply the knowledge they have learned, choose the project orientation, design the experimental plan and arrange the laboratory instruments in a coordinated manner; and they can install and debug the instruments, complete the data processing independently and obtain the ideal experimental result. It can strengthen the cultivation of students' innovative consciousness and practical ability and provide a useful way that can be learnt from of the reform of pharmacology experiment teaching for undergraduates by actively improving the institutional guarantee of the open pharmacology experimental teaching system, strengthening the hardware support for the experimental platform, building an experimental teaching sharing platform and ensuring the experimental team support [7], which is of great significance in the process of undergraduate learning and growth.

\section{REFERENCES}

[1] Joseph R. V. Flora, Adrienne T. Cooper, Incorporating Inquiry-Based Laboratory Experiment in Undergraduate Environmental Engineering Laboratory[J].Journal of Professional Issues in Engineering Education and Practice.2005, 131: 19-25.

[2] Tu Xiong. Boldly Establishing an Open Teaching Concept and Conscientiously Cultivating Students' Core Literacy [J]. Science and Technology: Science Education. 2017 (3): 76.

[3] Li Zhonghao, Wang Li, Qin Ruiling et al. Application of Integrated Open Teaching Mode in Immunology Teaching [J]. Chinese Journal of Immunology.2016, 32(1): 109-110.

[4] Miller K R. Finding the Key-cell Biology and Science Education[J. Trends in Cell Biology, 2010, 20(12):691-694.

[5] Xie Chuan, Luo Chongjian, Huang Huanli et al. Deepening Experimental Teaching Reform and Open Experiment Teaching Comprehensively [J].Higher Education in Chemical Engineering.2004, 79: $107-108$

[6] Qin Xiaojing. Cultivating Innovative Talents through Open Experiment Teaching [J]. Experimental Technology and Management.2005, 22: 8789.

[7] Yin Liping. Promoting the Open Sharing of Laboratories with the Cultivation of Practical Innovation Ability as the Core [J].Experiment Science and Technology. 2015, 13(5): 229-231, 251. 